\title{
Involvement in Video Material: Concept Mapping
}

\author{
Nele Van den Ende \\ Philips Research \\ HTC $34-5.62$ \\ $\mathrm{NL}$ - 5656Ae Eindhoven \\ 0031402749536
}

nele.van.den.ende@philips.com

\author{
Jettie Hoonhout \\ Philips Research \\ HTC $34-5.07$ \\ $\mathrm{NL}$ - 5656Ae Eindhoven \\ 00314027447512
}

jettie.hoonhout@philips.com

\author{
Lydia Meesters \\ Eindhoven University of Technology \\ Den Dolech 2 \\ 5612 AZ Eindhoven \\ 00314024735351
}

I.m.j.meesters@tue.nl

\begin{abstract}
Involvement is an important mediating factor in judgements concerning user experience. Concept mapping was used to further understand and define the construct of involvement within the context of watching television.
\end{abstract}

\section{Categories and Subject Descriptors}

J.4 Social and behavioral sciences

\section{Keywords}

Involvement, Concept mapping, Card sorting, User experience

\section{INTRODUCTION}

It is likely that the involvement a person feels while watching video material such as films or television programs, varies greatly. Research into the advertising domain has shown that involvement is a mediating factor between personal, situational and stimulus factors and purchase decisions [7]. Considering that watching video material is an integral part of gaming and interactive television, it is important to find out which mediating effect involvement has on user experiences with video material. However, before any questions concerning the influence of involvement can be answered, it is necessary to define the construct of involvement and to develop or adopt a measure which can capture involvement of the viewer, both the state of the moment and strength of tendency of viewers to become involved in the first place $[1,2]$.

Witmer \& Singer [6] developed the Immersive Tendencies Questionnaire (ITQ) to be able to measure differences in experiencing presence (but not necessarily in the context of TV watching). While Witmer \& Singer concentrate on presence, Klimmt \& Vorderer argue that presence can be a special case of involvement - or involvement a special case of presence [2]. Hence, looking at presence literature and questionnaires to study involvement gave further input for our research. The ITQ has two main factors: involvement and focus. Involvement items inquire about people's tendency to be passively involved in an activity (e.g. reading a book, watching television). To illustrate, some example items are "Do you ever become so involved in a movie that you are not aware of things happening around you?" and "How frequently do you find yourself closely identifying with the characters in a story line?". Focus items inquire more about people's current state of mental alertness, ability to concentrate on congenial activities and ability to block distracters. Example items are: "Do you easily become deeply involved in movies or TV dramas?" and "Do you ever become so involved in doing something that you lose all track of time?".
We believe that these questions tap only little, i.e. at a general level, of what involvement is. For our studies into the impact of involvement we need a reliable and valid measurement tool. To develop such a tool, it is important to define the concept or construct of involvement first, and in more detail than currently existing constructs. An approach called concept mapping [5] was employed, which should lead to a satisfactory operational definition of involvement. First, several notions and ideas around involvement will be discussed, then concept mapping is briefly described, and last the steps taken so far to define the involvement construct are discussed and future work is summarily outlined.

\section{NOTIONS ABOUT INVOLVEMENT}

Involvement can be characterised as a consequence of the relation between a person and an object or activity, as well as the meaningfulness of this relation [6]. It has also been postulated that there is a low and a high level of involvement $[2,3]$. During low involvement, people are aware that their experience is mediated. During high involvement, people no longer feel that their experience is mediated. High involvement has also been referred to as affective involvement, while low involvement has been referred to as cognitive involvement [4]. Consumer behaviour research, however, has suggested that levels of involvement are relative to each other, rather than varying on a one-dimensional scale [3]. Considering that there is still no consensus about how involvement is defined, understanding exactly how it applies to different conditions is not straightforward. Therefore, it is necessary to further define the construct of involvement specifically in the area of watching video material.

\section{CONCEPT MAPPING}

Concept mapping as described by Trochim [5] is a structured method which can be used to develop a conceptual framework, e.g. a worked-out definition of measurement. It has been conclusively shown that concept mapping can help with operationalizing definitions, albeit in a different field. Concept mapping gives a structured way to reach an operationalized definition of involvement. To that end, interviews were conducted to generate statements (instead of a brainstorm), and the statements were structured through an individual unstructured card sorting procedure. The representation of the statements will be reached through hierarchical cluster analysis.

\section{DEFINING INVOLVEMENT FURTHER}

We carried out the preparatory phase of concept mapping (as described in [5] and decided that instead of using a brainstorm procedure, semi-structured interviews would be used to elicit statements. This would give the opportunity to visit participants at home, where more clues are available about their behaviour 
towards video material. Interview questions were based on the ITQ questions, a Presence Questionnaire [6], and earlier definitions of involvement [2-4]. Statements elicited during the interviews were then used to prepare a pilot card sorting task.

\subsection{Interviews}

\subsubsection{Method}

Six semi-structured interviews were carried out in Dutch, with two women and four men (age range 17 - 34). After asking some warming-up questions, participants were asked general questions about involvement, such as: did they ever feel so involved in a program, movie or a book that other people had trouble getting their attention? This should indicate whether they ever feel involvement at all, and at which level [6]. Next, they were asked to describe their favourite program on television (including movies), and whether or not they felt involved, and if so, why were they involved. They were also asked to give words that described how they watched video material. Interviews were transcribed, and the transcriptions are discussed briefly in the next section.

\subsubsection{Results}

Words that came up during the interviews to described watching video material were: interest (3), entertainment (3), relaxing (2), pastime (2), escapism, observing other people, cosy together, challenge, fun, occupation, and not selfabsorbed.

During the interviews, most people mentioned involvement, but they also mentioned 2 other important things (translated from Dutch): sympathise with (meevoelen met) and absorbed in/caught up in (opgaan in). Participants were also asked to give their own definition of involvement, sympathise with and being absorbed in / caught up in. Based on these definitions, the words used to describe watching video material and other statements uttered during the interviews, the pilot card sorting task was devised.

\subsection{Card sorting}

\subsubsection{Method}

Fifty words and expressions which were given either as (1) pertaining to involvement, (2) being absorbed in or sympathise with or (3) which expressed some kind of behaviour pertaining to involvement or watching television were written on cards. Examples are: replaced embarrassment, talking to the TV, fiddling, understanding, commiserate, identify with, sympathise with, feel compassion, concern, and horrified. In a pilot test, four male participants were given the 50 cards and asked to sort the cards into meaningful categories. Participants were explicitly told that the amount of categories did not matter.

\subsubsection{Results}

After gathering their category descriptions, the results were used for hierarchical cluster analysis (HCA). Based on how often words were grouped together in a category, five clusters were made by the HCA (unweighted average distance, or group average). It is of interest that 'involvement' and 'sympathise with' belong to the same cluster, but 'absorbed in' belongs to a different cluster. 'Comprehension' and 'interest' also belong together, but are more seen as related to 'involvement' and 'sympathise with' than with 'absorbed in'.
Remarks from the subjects showed that the card sorting task could be improved if three items were taken out: interested, which was a double word; kinship, which was not well understood; and luxuriousness, which was classified as unrelated 4 times. Five items were changed to make them better understandable, such as elucidating "feeling embarrassed for something somebody else did" (plaatsvervangende schaamte).

Based on the HCA, remarks from the subjects, a review of the literature and the transcriptions of interviews, 9 words were added: boring, challenge, communication, curiosity, frightening, immersed, relaxing, suspension of disbelief and turning of the TV. The new card sorting task was given to 16 native English speakers, of which the results will be shown on the poster.

\section{DISCUSSION}

Based on the interviews and the card sorting pilot, theories which suggest a clear distinction between high and low involvement are supported [2]. Results from the pilot indicate that situational and personal characteristics also play a role for involvement in general video material. Object or stimulus factors as defined in [7] were not explicitly included in the card sorting task. However, how much of the feeling of involvement is due to the state people are in? How much is due to a trait they have? Would this mean that some people are inherently more easily involved than others? And if so, how could state and trait be tested? Involvement is likely to be a highly changeable state, due to interactions and distractions which can occur while people are watching TV programs, are gaming or using interactive televisions. It is clear that, before deciding on measurement options, a further refinement of the involvement concept is necessary, such that a reliable and valid measurement tool can be made.

\section{FUTURE WORK}

We plan on running further card sorting and other tasks to confirm or deny current clusters and detail the construct of involvement, to operationalize the definition of involvement.

\section{REFERENCES}

[1] Clark, L. A. and Watson, D. Constructing validity: Basic issues in objective scale development. Psychological Assessment, 7, 3 (Sep 1995), 309-319.

[2] Klimmt, C. and Vorderer, P. Media psychology "is not yet there": Introducing theories on media entertainment to the presence debate. Presence-Teleoperators and Virtual Environments, 12, 4 (Aug 2003), 346-359.

[3] Nillesen, J. P. H. Involvement en reclameverwerking. De Vrieseborch, City, 1988.

[4] Perse, E. M. Implications of cognitive and affective involvement for channel changing. J. Commun., 48, 3 (Sum 1998), 49-68.

[5] Trochim, W. M. K. An introduction to concept mapping for planning and evaluation. Evaluation and Program Planning, 121989), 1-16.

[6] Witmer, B. G. and Singer, M. J. Measuring presence in virtual environments: A presence questionnaire. PresenceTeleoperators and Virtual Environments, 7, 3 (Jun 1998), 225240.

[7] Zaichkowsky, J. L. Conceptualing involvement. Journal of Advertising, 15, 2 1986), 4-14. 